\title{
IPA NEWS
}

\author{
IN MEMORIAM \\ JOHAN LILJENCRANTS (1936-2012)
}

Johan Liljencrants was a KTH oldtimer. His interests focused early on speech analysis and synthesis where in the 1960s he took a leading part in the development of analysis hardware, the OVE III speech synthesizer, and the introduction of computers in the Speech Transmission Laboratory. Later work shifted toward general speech signal processing, for instance in his thesis on the use of a reflection line synthesizer. His interests expanded to modelling the glottal system, parametrically as in the Liljencrants-Fant (LF) model of glottal waveshapes, as well as physically including glottal aerodynamics and mechanics.

When Johan Liljencrants started out at the beginning of the 1960s at Gunnar Fant's lab at KTH as a thesis student, the exhaustive work on the theory of speech production had materialized in the manually controlled OVE I synthesizer, a couple of heavy electronics boxes and a big drawing-board to control pitch and formants. Soon the OVE II synthesizer was completed. It could produce synthetic speech of an amazingly good quality. With one important proviso, you had to spend a month or so to produce two seconds of good sounding speech. It seemed necessary to perfect the analysis instrumentation in order to get better data than could be obtained with the fragile Sona-Graph of yesterday. New electronic components paved the way for a new piece of analysis hardware, the flexible 51-channel filter bank. It was made to also include the novel digital technique of recording the output data. It contained a custom built logarithmic $\mathrm{A} / \mathrm{D}$ converter appropriate for representing speech. It later became the main front end for early speech recognition research in the 1970s.

In 1967 the department inaugurated a new toy, a CDC 1700, as the second institution at KTH with an in-house dedicated computer. Johan took a leading part in the development of analysis software and hardware. Modern techniques with integrated circuits were the base for OVE III, designed by Johan. The synthesizer was controlled by a computer program utilizing the ideas of smoothed step functions in an elegant fashion.

At an early stage the importance of the glottal source was realized, and detailed work by Gunnar Fant, John Holmes, Jan Lindqvist Gauffin and Martin Rothenberg led to ways to increase the naturalness considerably. This work was finally implemented as the LF-glottal source (Liljencrants-Fant glottal source), a reference model still used in many research efforts and applications.

Johan was amazingly productive, not so much in terms of traditional academic reporting, but in terms of devices, methods, programs and ideas that made life so much more interesting and easy for many of us, his colleagues in the department. During four decades he was possibly the most important scientific support and discussant partner to Gunnar Fant. In a special issue of the department report STL-QPSR on the occasion of Gunnar Fant's 60th birthday, Johan characterized himself as the conjurer's apprentice (TMH-QPSR 20(2), 1-45; http://www.speech.kth.se/qpsr/).

Johan was a very inspiring and appreciated teacher. Many generations of KTH students remember his Electroacoustics class with a multitude of novel and fascinating demonstrations. He also created the appropriately named Fonema company, where he produced research hardware, like the digitally controlled OVE III synthesizer, used in many laboratories. Johan also produced a small-size replica of OVE I, mainly intended for teaching. He also produced software for use in training and rehabilitation for e.g. persons with dyslexia. Another interesting example is the Fonem program used for experimenting with consonant and vowel production, through an early 'talking head', an animated midsagittal head, where the articulators could be manipulated and the resulting speech could be listened to. As an expert, Johan was engaged as the author of many articles in the last Swedish large-scale encyclopedia (Nationalencyklopedin, 1989-1995) in the areas of speech and acoustics. 
After retirement, the Fonema company web site developed into a comprehensive account of his wide interests, also outside the area of speech communication. There he describes himself as: 'Beside his private interest in music he indulges in various handicrafts like singleline flying kite design, carpentry, sewing, bottleship building, silver forging, and gem facet cutting' (http://www.fonema.se). The music interest not only included playing the trumpet in the department's Formant Orchestra but also constructing and building a street organ from scratch (http://www.fonema.se/organ/organ.htm).

As the reader now must appreciate, Johan was an exceptionally talented and multifaceted person. We miss him a lot as a researcher and a fellow human being. His kite hanging from the ceiling of our lunchroom brings many happy memories.

For friends and colleagues at the department of Speech, Music and Hearing, KTH,

Rolf Carlson \& Björn Granström

Royal Institute of Technology (KTH), Stockholm, Sweden 